\title{
A study to assess the selfitis behaviour and selfie syndrome (level of selfitis) among the nursing students
}

\author{
Singh V. ${ }^{1}$, Yadav A. ${ }^{2}$ \\ ${ }^{1}$ Mr. Virendra Singh, Nursing Lecturer, Govt. College of Nursing, SPMC, Bikaner, Rajasthan, ${ }^{2}$ Dr. Ashok Yadav, \\ Nursing Lecturer, Govt. College of Nursing, SMS, Med. College, Jaipur, Rajasthan, India.
}

Corresponding Author: Mr. Virendra Singh, Nursing Lecturer, Govt. College of Nursing, SPMC, Bikaner, Rajasthan, India. E-mail: singhvirendra809@gmail.com

\begin{abstract}
Background: Photography is seen as a powerful means of expression, as a symbolic language to express what cannot be said in words, and as a stimulator of emotions and behaviors about which often are not aware. The term the word "selfie", is declared as the "word of the year" by the Oxford English Dictionary. Selfie fever has taken a new dimension known as 'selfitis'. Objectives: To assess the selfitis behavior, the selfie syndrome (level of selfitis) and find out significant association of selected background variables with selfie syndrome (level of selfitis) among nursing students. Material and Methods: It is a non-experimental study carried out on the nursing students in nursing training institutes in Bikaner city, Rajasthan. A study was conducted during the year of 2018 and 200 nursing students who are under training of GNM, B.Sc. nursing and M.Sc. Nursing were selected by using multi stage random sampling. Self developed questionnaire, Selfitis behavior scale and structured questionnaire used to collect the date from participants. Results: Based on the finding of the majority of 141(70.5\%) nursing students has moderate selfitis behavior followed by 59(29.50\%) nursing students has severe Selfitis Behaviour and no candidate has mild Selfitis. The mean score of selfitis behaviour was 62.595 with SD 12.334. Based on findings there was no significant association of back ground variable with the level of selfitis except type of course in which student is admitted for nursing training. Conclusion: The present study has proved that selfie syndrome is dominantly developing craze of modern era due to modern fat changes in technologies. From the finding of the present study it is concluded that the majority of nursing students have moderate selfitis behaviour.
\end{abstract}

Key words- Selfitis behavior, Selfie syndrome, GNM, B.Sc. Nursing, M.Sc. Nursing

\section{Introduction}

The first to have captured value therapeutic photography field of mental health was Hugh Diamond (1856), [1] amateur photographer and in 1914. "Selfie discussed first by photographer Jim Krause in 2005, although the picture in the genre of dating using selfie wide of the term. In 2010 Selfie had gained a wide popularity in social media. Art selfie is one that many people have practiced and perfected over the years, although the habit of publishing photos on social networks was born in 2000 with the creation of the first areas in social networks [2].

The rapid growth of Social Networking Sites (SNS's) as well as Smartphone has resulted in a new addiction i.e. 'Selfie fever' [3].

Manuscript received: $14^{\text {th }}$ November 2018

Reviewed: $24^{\text {th }}$ November 2018

Author Corrected: $30^{\text {th }}$ November 2018

Accepted for Publication: $5^{\text {th }}$ December 2018
According to a study by Jillian McHugh on 3 April 2013, two thirds of women aged 16-35 make selfie order posting on facebook [1,4] The rapid growth of Social Networking Sites (SNS's) as well as Smartphone has resulted in a new addiction i.e. 'Selfie fever' [4].

Selfitis: According to APA selfitis is defined as an obsessive compulsive desire to take photos of self. It is disorder characterized by a person's desire to look good continuously and to show it to others. The following are the types of selfitis based on frequency and sharing socially [4].

Borderline Selfitis- Up to three selfies per day, but not sharing on social media

Acute Selfitis- Three selfies per day, and sharing them on social media. 
Chronic Selfitis- At least six selfies per day and sharing every selfie on social media. Selfie fever made people to portrait them and use them as an object for likes and comments only. It is also a true fact that some of the person considers selfie as a token of memorable moments.

The self projected object known as selfie are exhibiting the true and actual behavior of the particular person. The entry of selfie to new generation's world has replaced a major portion of traditional photography. Smartphone industry invented front cameras in their phone just to attract new customers and to increase sale and thus to maximize their profit.

Contributing to this the preference for front camera phones has been increased dramatically within few years. There are various studied at international and national level that stated Selfitis- Selfie Craze and Addiction or selfitis is obsessive compulsive disorder or new mental disorder of modern era [4].

Selfitis is a current problem for mental health in world of fast growing modern technology and less no of study are conducted in Rajasthan so researcher select the present study with purpose of assessing selfitis behavior and selfie syndrome for baseline and further analysis of study.

\section{Material and Methods}

Research approach: Quantitative research approach

Research design: Non- experimental Descriptive research design

Setting of the study: Nursing institutes of Bikaner city (Rajasthan).
Population- All nursing students who are under training for GNM, B.Sc. Nursing and M.Sc. Nursing course in nursing institutes of Bikaner city (Rajasthan).

Sampling technique: Multi stage random sampling technique.

Inclusion Criteria- Samples were selected for study who

- Were willing to participate in study

- Were admitted in only nursing institutes of Bikaner City.

- Were available at the time of data collection.

\section{Exclusion Criteria}

- Were not willing to participate in study.

- Were not admitted in only nursing institutes of Bikaner City.

- Were not available at the time of data collection

\section{Tool for Data collection}

1. Part-I: Background Variables (Age, sex, residence, type of institute, course in which admitted and occupation of father).

2. Part-II: Selfitis behavior scale to assess selfitis behavior among the nursing students at nursing institutes of Bikaner city (Rajasthan)

3. Part-III: structured questionnaire to assess selfie syndrome (level of selfitis) among the nursing students at nursing institutes of Bikaner city (Rajasthan)

\section{Scoring System}

(A) Selfitis Behaviour Scale.

\begin{tabular}{|c|c|c|}
\hline S. No. & Score & Category of Selfitis Behaviour \\
\hline 1 & $0-33$ & Mild selfitis behaviour \\
\hline 2 & $34-67$ & Moderate selfitis behaviour \\
\hline 3 & $68-100$ & Severe selfitis behaviour \\
\hline
\end{tabular}

(B) Selfie syndrome (level of selfitis)

Borderline Selfitis- Up to three selfies per day, but not sharing on social media

Acute Selfitis- Three selfies per day, and sharing them on social media

Chronic Selfitis- At least six selfies per day and sharing every selfie on social media

Data Analysis: Descriptive statistics, inferential statistics. 


\section{Results}

The findings are summarized as follows:

1. Majority of 141(70.5\%) nursing students has moderate selfitis behaviour followed by 59(29.50\%) nursing students has severe Selfitis Behaviour and no candidate has mild Selfitis Behaviour. The mean score of selfitis behaviour was 62.595 with SD 12.334 .

2. Majority of $147(73.50 \%)$ sample were at level of borderline selfilis followed by $41(20.5 \%)$ sample were at level of acute selfitis and $12(6 \%)$ samples were at level of chronic Selfitis.

3. The study show that most of the background variables indicate no significant association with level of selfitis except type of course in which admitted. So alternative hypothesis is partially rejected and researcher failed to reject the null hypothesis at .05 level of significance.

Table No.-1: Frequency and percentage distribution of the sample characteristics Age, Sex, Residence, Type of Nursing Institute, Course in which admitted, Occupation of father.

$\mathbf{N}=\mathbf{2 0 0}$.

\begin{tabular}{|c|c|c|c|}
\hline Sr. No. & Demographic Characteristics & Frequency $\{\mathbf{f}\}$ & Percentage $\{\%\}$ \\
\hline 1. & Age in Years & & \\
\hline A & $17-20$ & 141 & 70.5 \\
\hline \multirow[t]{2}{*}{ B } & $21-24$ & 34 & 17.0 \\
\hline & $25-28$ & 25 & 12.5 \\
\hline 2. & Sex & & \\
\hline $\mathrm{A}$ & Male & 105 & 52.5 \\
\hline $\mathrm{B}$ & Female & 95 & 47.5 \\
\hline 3. & Residence & & \\
\hline $\mathrm{A}$ & Rural & 61 & 30.5 \\
\hline $\mathrm{B}$ & Urban & 139 & 69.5 \\
\hline 4. & Type of Nursing Institute & & \\
\hline A & Private & 95 & 47.50 \\
\hline $\mathrm{B}$ & Government & 105 & 52.5 \\
\hline 5. & Course in which admitted & & \\
\hline $\mathrm{A}$ & G.N.M. & 57 & 28.5 \\
\hline $\mathrm{B}$ & B.Sc. Nursing & 112 & 56.0 \\
\hline $\mathrm{C}$ & M.Sc. Nursing & 31 & 15.5 \\
\hline 6. & Occupation of father. & & \\
\hline A & Government & 65 & 32.5 \\
\hline $\mathrm{B}$ & Private & 57 & 28.5 \\
\hline $\mathrm{C}$ & Agriculture & 78 & 39.0 \\
\hline & Total & 200 & $100 \%$ \\
\hline
\end{tabular}

Table No.-2: Frequency and percentage distribution of the selfitis Behaviour with Mean and standard deviation among Nursing Students

$\mathrm{N}=\mathbf{2 0 0}$

\begin{tabular}{|c|c|c|c|c|c|}
\hline Sr. No. & $\begin{array}{c}\text { Selfitis Behaviour } \\
\text { (Category) }\end{array}$ & Frequency $\{\mathbf{f}\}$ & Percentage \% & Mean & SD \\
\cline { 1 - 3 } 1 & Mild Selfitis Behaviour & 00 & $00 \%$ & \multirow{2}{*}{62.595} & \multirow{2}{*}{12.334} \\
\cline { 1 - 4 } 2 & Moderate Selfitis Behaviour & 141 & $70.5 \%$ & $29.50 \%$ & \\
\hline
\end{tabular}


Table No.-3: Frequency and percentage distribution of selfie syndrome (level of selfitis) the with Mean and standard deviation among Nursing Students.

$\mathbf{N}=\mathbf{2 0 0}$.

\begin{tabular}{|c|l|c|c|}
\hline Sr. No. & Level of Selfitis (Selfie Syndrome) & Frequency $\{\mathbf{f}\}$ & Percentage $\%$ \\
\hline 1 & Boderline Selfitis & 147 & $73.5 \%$ \\
\hline 2 & Acute Selfitis & 41 & $20.5 \%$ \\
\hline 3 & Chronic Selfitis & 12 & $6 \%$ \\
\hline \multicolumn{2}{|c|}{ Total } & $\mathbf{2 0 0}$ & $\mathbf{1 0 0}$ \\
\hline
\end{tabular}

Table No.-4: Frequency and percentage distribution of selfie syndrome (level of selfitis) the with Mean and standard deviation among Nursing Students.

\begin{tabular}{|c|c|c|c|c|c|}
\hline Sr. No. & Back ground Variables & Chi Square value & $\begin{array}{c}\text { Degree of } \\
\text { Freedom (df) }\end{array}$ & $\begin{array}{c}\text { Tabulated } \\
\text { value }\end{array}$ & \\
\hline 1 & Age & 3.409 & 6 & 12.6 & $\mathrm{NS}^{*}$ \\
\hline 2 & Sex & 6.878 & 3 & 7.81 & $\mathrm{NS}^{*}$ \\
\hline 3 & Residence & 1.814 & 3 & 7.81 & $\mathrm{NS}^{*}$ \\
\hline 4 & Type of Institute & 3.360 & 3 & 7.81 & $\mathrm{NS}^{*}$ \\
\hline 5 & Course Type & 13.107 & 6 & 12.6 & $\mathrm{~S}^{*}$ \\
\hline 6 & Occupation of Father & 10.654 & 6 & 12.6 & $\mathrm{NS}^{*}$ \\
\hline
\end{tabular}

$\mathrm{NS}^{*}=$ Not Significant $\mathrm{S}^{*}=$ Significant

Analysis of selfitis behaviour among nursing students- Finding of the present study revealed that majority of $141(70.5 \%)$ nursing students has moderate selfitis behaviour followed by 59(29.50\%) nursing students has severe Selfitis Behaviour and no candidate has mild Selfitis Behaviour. The mean score of selfitis behaviour was 62.595 with SD 12.334.

Analysis of level of selfitis among nursing students- The finding of the study revealed that majority of $147(73.50 \%)$ sample were at level of borderline selfilis followed by $41(20.5 \%)$ sample were at level of acute selfitis and $12(6 \%)$ samples were at level of chronic Selfitis.

\section{Associate the selected background variables with the level of selfitis (selfie syndrome).}

The calculated value of the $\chi 2$ for the sample characteristics age was 3.409 with df-6, followed by sex was $6.878^{*}$, for residence was $1.814 *$ and type of institute was $3.360 *$ with $\mathrm{df}-3$ for course type was $13.107 *$ and for occupation of father was $10.654 *$ with $\mathrm{df}-6$ respectively at the level of $\mathrm{p}<0.05^{* * *}$.

The calculated value of Chi square with background variable was less than tabulated value with specify df excepting type of course in which admitted.

The study show that most of the background variables indicate no significant association with level of selfitis except type of course in which admitted. So alternative hypothesis is partially rejected and researcher failed to reject the null hypothesis at .05 level of significance.

\section{Discussion}

The present study is an effort to assess the selfitis behaviour and selfie syndrome (level of selfitis) among the nursing students. In order to achieve the objective of the study a non experimental descriptive design was adopted. 200 samples were selected by using probability sampling technique, fulfilling the criteria of sample. There was no enough study conducted but there viewed study supported the present study for large extent. 


\section{Original Research Article}

Finding of the present study revealed that majority of $141(70.5 \%)$ nursing students has moderate selfitis behaviour followed by $59(29.50 \%)$ nursing students has severe Selfitis Behaviour and no candidate has mild Selfitis Behaviour. The mean score of selfitis behaviour was 62.595 with SD 12.334. Findings of study supported by study conducted. The finding of present study supported by study conducted by Veena. G (2015) co regarding perception towards capturing selfies and its impact among students of Mangalore University and the research employed survey method was conducted using a well structured questionnaire.

120 respondents participated through convenience sampling for this research. The finding of the study shows that majority $85(70.83 \%)$ of respondents after taking selfies send them via whats app, 76(71.66\%) of students states that taking a selfie can turn deadly. It was found from the study $62(51.66 \%)$ of the respondents determined with the statement taking selfies is a waste of time [3], near about similar finding were supported by Vats. M. (2015) conduct a study, Selfie syndrome: An Infectious Gift of IT to Health Care and state exact prevalence is not known but as per the experts, approximately $40 \%$ or higher percentage of teenage, young and adult population in the developed world are suffering from the selfie syndrome with the manifestations varying from mild to severe [5].

Finding of present study supported by cross sectional study conducted by Satish Saroshe, Ruchita Banseria et al (2014) regarding assessment of selfie syndrome among the professional students of a cosmopolitan city of central India and finding around $11 \%$ people accepted that they take selfies daily, $3 \%$ said they take selfies for attention, $31 \%$ said they had other reasons for taking selfies, self-objectification and narcissism. Overall $29 \%$ people have done something crazy to look nice for a selfie, $16 \%$ of people had negative experience with posting selfies on social media [6].

Bhardwaj. A, Avasthi. V, Goundar. S. conduct a survey study on impact of social Net working on Indian Youth showed that the extensive use of Social Networking in India has been on the rise among the new generation youths. In today's world life can not be imagined without Face book, You tube, Instagram, whats App, LinkedIn or Twitter accounts and online handles. The new age social networking cultures have been well accepted and have met an enthusiastic response and acceptance. These finding also possibly provoke the seifie syndrome among the young generation and have relationship with the present study [7].
The study show that most of the background variables indicate no significant association with level of selfitis except type of course in which admitted. Thakur $\mathrm{N}$ et al conduct study which showed that there is significant association between selfie taking behavior and level of social health (attention seeking behaviour) among late adolescents which project the value of Fisher's exact is .05 which is significant at $\mathrm{p}=0 . .05$, but there was no significant association between selfie -taking behavior and loneliness behavior in late adolescent $(\mathrm{p}>0.05)$ [8].

A similar study that indirectly have relationship with present study conducted by Kela $\mathrm{R}$ et al to know the complication of taking selfie out of the 250 Students, students suffering from low back ache were 30\%, students suffering from stress were $15 \%$, students suffering from cervical spondylitis were $20 \%$, students suffering from headache were $25 \%$ and students suffering from selfie elbow were $10 \%$ [9].

Mrs. Sonalika S. conduct an exploratory study and findings revealed that majority of respondents $88(55 \%)$ had inadequate knowledge, 57 (37.62\%) were had moderate knowledge regarding selfitis that provide basis for selfitis and had relationship with the present study [10].

Kaur Sukhdeep \& Maheswari SK Conduct a study Narcissistic personality and selfie taking behavior among college students support the present study and findings were $5.3 \%$ of college students were taking $>15$ number of selfies per day and preferred to took selfies with their friends (41.3\%). Nearly two third $(64.66 \%)$ of college students preferred group selfie with joy as dominant emotions $(90.3 \%)$. Having love clicking themselves was the most preferred group reason for clicking selfies $(39 \%)$. More than two third $(70 \%)$ of college students upload selfies on social sites preferably on whatsapp $(77.3 \%)$, more than half $(60 \%)$ of college students sometimes edit their selfies before posting them and $44.5 \%$ of college students never untag themselves from group selfies [11].

\section{Conclusion}

The present study has proved that selfie syndrome is dominantly developing craze of modern era due to modern fat changes in technologies. From the finding of the present study it is concluded that the majority of nursing students have moderate selfitis behaviour. The present study recommend to comparative study to assess the selfie syndrome among male and female, to assess the impact of selfie syndrome on personatilty, assessment of prevalence of selfie syndrome among the 


\section{Original Research Article}

adolescence. Factor analysis can be performed for identify the specific factor for taking selfie. Based on the finding of the majority of $141(70.5 \%)$ nursing students has moderate selfitis behaviour followed by 59 $(29.50 \%)$ nursing students has severe Selfitis Behaviour and no candidate has mild Selfitis. The mean score of selfitis behaviour was 62.595 with SD 12.334 .

This study was a descriptive study that provide the baseline information about the selfie syndrome and selfitis behavior but study helpful in developing awareness about selfie syndrome.

\section{Contribution of Authors}

1. Mr. Virendra Singh- Concept Design, tool development, conducting study and writing the manuscript.

2. Dr.Ashok Yadav- Guided and supervise the study procedure like problem statement, formation of tool for data collection, study conduction, Analysis and interpretation of data and preparing the manuscript suitable for publication.

Funding: Nil, Conflict of interest: None Permission of IRB: Yes

\section{References}

1. Psychological study project The Psychologically Beneficial Aspects of Photography, Adam Natoli, Dr. John Suler in Psychology Department of Rider University 2011 available at www.truecenterpublishing. com

2. Katz J.E. and Crocker E.T. Selfies and photo messaging as visual conversation: Reports from the United States, United Kingdom and China. International Journal of Communication, 9 (2015), (1861- 1872. 1932-8036/2015FEA0002.

3. Veena. G: Perception towards capturing selfies and its impact among students of Mangalore University: A Study International Journal of Digital Library Services Online available on www.ijodls
4. Albury K. (2015). Selfies, sexts, and sneaky hats: Young people's understandings of gendered practices of selfie presentation. International Journal of Communication, 9,1734-1745.

5. Vats M, Selfie syndrome: An Infectious Gift of IT to Health Care. J Lung Pulm Respirres. 2015;2 (4):48.

6. Satish Saroshe, Ruchita Banseria et al: Assessment of Selfie Syndrome among the Professional Students of a Cosmopolitan City of Central India: A Cross-sectional Study Int J Ment Health Addiction https://doi.org/ 10.1007/s11469-017-9844-x

7. Bhardwaj. A, Avasthi. V, Goundar. S; Impact of Social Net working on Indian Youth-A Survey, International Journal of Electronics and Information Engineering; Vol.7PP 41-51, Sep.2017( DOI:10.6636/ IJEIE. 201709.7 (1).05) 41; available. https:www. researchgate. net/publication/322538324.

8. Thakur N, Gaikwad Dagdu A., Assess the Selfie Taking Behaviour and its Impact on the Health of late Adolescents with a view to Develop Awareness Program for selected University of Gurugram, Haryana, International Journal of Science and Research (IJSR), ISSN (Online):2319-7064, impact factor (20170:296).

9. Kela R, Khan N, Saraswat R, Amin B. Selfie: Enjoyment and Addiction, JMSCR January; 05(1): 15836-15840.

10. Mrs. Sonalika. S.; An exploratory study to assess the knowledge regarding Selfitis among Adolescents in colleges of Bhubaneswar, International Journal of Advances in Nursing Management, volume no:6, issue no. 1 ISSN Print: 2347-8632, ISSN Online:2454-2652.

11. Kaur Sukhdeep \& Maheswari SK Conduct a study Narcissistic personality and selfie taking behavior among college students, International Journal of Medical and Health research, ISSN:2454-9142, Impact Factor:RJIF5.54,Volume 4, Issue 5; May 2018,Page no. 56-60 available at medicalsciencejournal.com

\section{How to cite this article?}

Singh V, Yadav A. A study to assess the selfitis behaviour and selfie syndrome (level of selfitis) among the nursing students. Int J Med Res Rev 2018;6(08):452-457. doi:10.17511/ijmrr.2018.i08.09. 